\title{
A INTERRELAÇÃO FILOSÓFICO-LITERÁRIA DO PENSAMENTO DE SARTRE: BASES PARA UMA PSICOLOGIA FENOMENOLÓGICA DO EU
}

\author{
Interfaces between Philosophy and Literature in Sartre: Grounds for a Phenomenological \\ Psychology of the Self \\ Inter-relación Filosófico-Literaria en el Pensamiento de Sartre: Bases para una Teoría \\ Fenomenológica del Ego
}

Carolina Mendes Campos

FERNANDA Alt

Ariane P. EWALD

\begin{abstract}
Resumo: Na mesma época em que publica seus primeiros trabalhos filosóficos, Jean-Paul Sartre inicia sua carreira no mundo literário. Seu pensamento possui a peculiar característica de expressar-se por diferentes vias e conseguir manter permanentemente aberto o canal entre filosofia e literatura, o que Franklin Leopoldo e Silva entende como uma vizinhança comunicante. Deste modo, a narrativa filosófica (técnica e conceitual) e a literária (estética) mantém uma espécie de ligação interna que permite estudar esta interrelação de modo a apreender o pensamento de Sartre em toda sua riqueza. É sob esta perspectiva que pretendemos explorar o conto de 1939 A infância de um chefe, um dos primeiros trabalhos literários do autor, desenvolvido na mesma época em que construía as bases de uma possível Psicologia Fenomenológica. O conto retrata a vida de Lucien Fleurier partindo de sua infância e acompanhando o processo pelo qual em diferentes tempos e situações ele procura redefinir seu projeto existencial. Deste modo, Sartre coloca em cena, através da narrativa, muitas das noções presentes neste processo que acaba por expressar nas entrelinhas bases para uma teoria fenomenológica do eu em comum acordo com seu trabalho filosófico $A$ transcendência do ego. Nosso trabalho objetiva, portanto, utilizar este texto literário como ponto de apoio para o estudo de uma teoria fenomenológica do eu, tal como foi esboçada por Sartre em ambas as vias filosófica e literária. Baseado na intencionalidade da consciência, o filósofo dirige suas críticas às noções formais e substanciais do eu que eram aceitas na filosofia e psicologia de seu tempo e que de certo modo perduram ainda no pensamento de hoje. Visões estas que suprimem o modo de ser da condição humana que se caracteriza pela liberdade, expressa pelo nosso personagem Fleurier pela angústia que vive ao tentar a todo custo escapar de sua inconsistência de ser.
\end{abstract}

Palavras-chave: Sartre; Psicologia Fenomenológica; Filosofia; Literatura; Fenomenologia do Self.

\begin{abstract}
While publishing his first philosophical texts, Jean Paul Sartre also initiates his career as a fictionist.Moving across a multiplicity of discourses, Sartre's thoughts find sound expression on the interfaces between philosophy and literature, forging a communicating neighborhood, in Franklin Leopoldo e Silva's terms. As a consequence, a kind of internal link between the philosophical narrative (technical and conceptual) and the literary narrative (aesthetic) allows for a full and rich comprehension of Sartre's writings. It's under the light of this understanding that we set out to explore the short story The childhood of a leader, 1939, one of Sartre's first literary texts, produced while he was working on the possible grounds for a Phenomenological Psychology. The story portrays the life of Lucien Fleurier from his early days as a child through a number of stages and situations in which he tries to redefine his existencial project. This way, Sartre weaves between the lines of his narrative several of the notions comprising that process, which end up settling the grounds for a phenomenological theory of the self, in keeping with his philosophical work entitled The transcendence of the ego. Therefore our work aims at using that literary text to support the study of a phenomenological theory of the self, as outlined by Sartre in both philosophical and literary fronts. Based on the intentionality of the consciousness the philosopher criticizes the formal and substantial notions of the self generally accepted by philosophy and psychology in his days, still persisting to date. Such understandings obliterate the way of being of the human condition, characterized by freedom, expressed by the distress our character Fleurier experiences trying his most to escape his inconsistency of being.
\end{abstract}

Keywords: Sartre; Phenomenological Psychology; Philosophy; Literature; Phenomenology of the Self.

Resumen: En la misma época en que publica sus primeros trabajos filosóficos, Jean-Paul Sartre inicia su carrera en el mundo litera. Su pensamiento posee la característica peculiar de expresarse por diferentes vías e conseguir mantener permanentemente abierto el canal entre filosofía y literatura, lo que Franklin Leopoldo e Silva entiende como una vecindad comunicante. De esa forma, la narrativa filosófica (técnica y conceptual) y la literaria (estética) se mantienen en una especie de conexión interna que permite estudiar esta inter-relación para aprender el pensamiento de Sartre en toda su riqueza. Es bajo esta perspectiva que pretendemos explorar el cuento de 1939 La infancia de un jefe, uno de los primeros trabaos literarios del autor, desarrollado en la misma época en que construía las bases de una posible Psicología Fenomenológica. El cuento retrata la vida de Lucien Fleurier 
partiendo de su infancia y acompañando el proceso por el cual en diferentes momentos y situaciones él busca redefinir s proyecto existencial. De esta forma, Sartre coloca en el escenario, a través de la narrativa, muchas de las nociones presentes en este proceso que acaba por expresar, en las entrelíneas, bases para una teoría fenomenológica del ego de común acuerdo con su trabajo filosófico La transcendencia del ego. Nuestro trabajo tiene el objetivo, por lo tanto, de usar este texto literario como punto de apoyo para el estudio de una teoría fenomenológica del ego, tal como fue delineada por Sartre en ambas vías, la filosófica y la literaria. Con base en la intencionalidad de la conciencia el filósofo dirige sus críticas a las nociones formales y substanciales del ego que eran aceptadas en la filosofía y la psicología de su tiempo y que de cierto modo todavía perduran en el pensamiento actual. Visiones estas que suprimen el modo de ser de la condición humana que se caracteriza por la libertad, expresada por nuestro personaje Fleurier por medio de la angustia que vive al intentar a todo costo escaparse de su incoherencia de ser Palabras-clave: Sartre; Psicología Fenomenológica; Filosofía; Literatura; Fenomenología del Ego.

\section{Introdução}

Foi a trajetória do pensamento de Jean-Paul Sartre nos anos 30 que inspirou o tema deste trabalho, por se tratar de um período em que o filósofo se propôs a estabelecer um diálogo crítico e direto com a psicologia de sua época. Este primeiro movimento teórico, que deu a Sartre reconhecimento no cenário intelectual francês dos anos do pré-guerra, mantém-se ainda, a nosso ver, como fonte rica de questionamento de noções psicológicas difundidas atualmente. Na França deste período, a Psicologia possuía uma orientação basicamente psicanalítica sobre o psiquismo humano e limitava a consciência numa visão substancialista, possuidora de conteúdos, e a noção de Ego como um habitante desta consciência ${ }^{1}$. Além disso, esta atmosfera intelectual do período contava também com a herança da filosofia tradicional, cujas vertentes, idealista e materialista, constituíam um dualismo difícil de ser superado.É, pois, neste contexto, que se inicia este caminho crítico do jovem intelectual Jean-Paul Sartre ao pensamento "dominante" de sua época, que inclui um questionamento direto a uma ciência relativamente recente e construída primordialmente por pressupostos positivistas, a Psicologia.

Entre 1933-34, Sartre foi estudar em Berlim com a intenção de conhecer mais profundamente a Fenomenologia de Husserl. Foi durante esta estadia que Sartre escreveu seu texto A transcendência do Ego: esboço de uma descrição fenomenológica ${ }^{2}$, e desde então deu continuidade a seus escritos com o objetivo de oferecer bases fenomenológicas para se pensar temas caros à Psicologia.

Paralelamente ao início de seu movimento teórico-intelectual, surgem também, as primeiras publicações dos seus escritos "literários". Em 1938, a editora dos irmãos Gallimard lança $A$ náusea, escrito em forma de diário íntimo do protagonista do romance, Antoine Roquetin (2005a). Como a articulação entre filosofia e literatura

\footnotetext{
Para uma contextualização deste período ver: Lottman (1987), Winock (2000).

2 Foi neste mesmo ano em Berlim que Sartre escreveu seu notável artigo sobre a noção de intencionalidade de Husserl, qualificado por Contat \& Rybalka (1970) como "sem dúvida, um dos melhores" (p.71, tradução nossa). Este pequeno texto encontra-se na coletânea Situations, I, (1947) traduzido e publicado no Brasil pela Editora Cosac \& Naify (2005), com prefácio de Bento Prado Jr.
}

foi sempre pregnante na obra de Sartre, é possível pensar que o surgimento de um romance neste mesmo período de amplo desenvolvimento teórico-filosófico não pode ser considerado como um movimento de descontinuidade de sua obra. Seu romance A náusea pode ser caracterizado como uma "narrativa psicológica" que, por tratar da experiência existencial do personagem principal frente ao vazio de sua condição humana, retrata, por uma outra via de expressão, as mesmas considerações do autor colocadas no plano filosófico. István Mészáros (1991), filósofo e ensaísta húngaro, chega a afirmar que "todos os elementos constitutivos da concepção geral do jovem Sartre estão presentes em A náusea" (p. 134) e que tais elementos conceituais se fundem, neste caso, uns aos outros, sob o efeito, porém, de um trabalho que os une a uma imaginação vívida. Em 1939, também pela Gallimard, é publicada uma coleção de contos intitulada significativamente de O muro (2005b). O tema central é inspirado na idéia de uma "liberdade emparedada" e fala das "situações limites" dos personagens que são colocados em xeque pelas circunstâncias das situações sendo forçados a (re)inventar uma saída. De acordo com Michel Contat e Michel Ribalka (1970), Sartre dirá que estes contos retratam, de diferentes maneiras, um fracasso de uma tentativa de fuga da liberdade. É portanto, já em 1939, que Sartre começava a desenvolver o tema que será posteriormente base de seu "teatro de situações", cujos "heróis são liberdades aprisionadas em armadilhas (...) Cada personagem será tão somente a escolha de uma saída e não valerá mais que a saída escolhida" (Sartre, 1999, p. 215). Ora, continua ele, delineando claramente a liberdade como base do teatro de situação,

cada situação é uma ratoeira, há muros por todos os lados: na verdade me expressei mal, não há saídas a escolher. Uma saída é algo que se inventa. E cada um, inventando a sua própria saída, inventa-se a si mesmo. O homem é para ser inventado a cada dia. (p. 215, grifo nosso)

Diante desta dupla perspectiva da obra sartriana, podemos dizer que seu pensamento possui a peculiar característica de expressar-se por diferentes vias e de conseguir manter permanentemente aberto o canal entre filosofia e 
literatura, o que Franklin Leopoldo e Silva (2004) entendem como uma vizinhança comunicante. Deste modo, a narrativa filosófica (técnica e conceitual) e a literária (estética) mantém uma espécie de ligação interna que permite estudar esta interrelação de modo a apreender o pensamento do filósofo existencialista em toda a sua riqueza. É sob esta perspectiva que exploramos A infância de um chefe, um dos contos que compõe a coletânea $O$ Muro de 1939, com o objetivo de tentar pensar uma possível relação desta produção literária com a teoria fenomenológica do eu desenvolvida em A Transcendência do Ego.

\section{O Ego está Fora, no Mundo: Fenomenologia do Ego}

O princípio básico com o qual Sartre inicia seu texto A Transcendência do Ego, é o de que "o Ego não está nem formal nem materialmente na consciência: está fora, no mundo; é um ser do mundo, como também o Ego do outro" (Sartre, 1996, p. 13, tradução nossa).

Para o existencialismo sartriano, não nascemos com uma essência prévia mas sim caminhamos para uma essência constituída, isto significa que não somos aprioristicamente determinados. Até mesmo em relação à noção de Ego, Sartre é contundente ao afirmar que nada precede a consciência, ela existe como pura espontaneidade e encontra sua fonte em si mesma. Deste modo, Sartre critica a idéia de um suposto Eu interiorizado que "habitaria" a consciência e analisa a constituição e a identificação de um Ego que seria exterior, pois se construiria a partir da experiência da consciência no mundo.

Em A transcendência do Ego, Sartre defende a tese de que devemos aprender a distinguir o "Eu" da "consciência" e concentra sua discussão em uma tentativa de compreender as relações existentes entre eles. Afirma que os problemas desta relação são existenciais e que, portanto, temos que nos voltar para Husserl e a fenomenologia (Sartre, 1994, p. 45). Este texto, como nos indica JeanMarc Mouillie (2000, p. 12), parte de uma afirmação de princípio, "o da impossibilidade de naturalizar a consciência, de lhe atribuir falsamente o modo de ser da coisa". Este princípio está na origem da sua discussão com a fenomenologia de Husserl e seu problema com o conceito de "ego transcendental" que Husserl expõe na Idéias I, reiterada nas Meditações Cartesianas, e que, para Sartre, é incompatível com o postulado da intencionalidade da consciência. ${ }^{3}$ Neste sentido, o caminho de Sartre é o do estabelecimento da consciência como instância autônoma, impessoal e intencional, demarcando que o ego não é uma propriedade interna da consciência, mas sim que ele se instaura pela transcendência, isto é, ele tira do mundo o seu conteúdo. Por isto ele está fora, é um ser

\footnotetext{
O texto do professor Simeão D. Sass (1999) é bastante elucidativo quanto a esta questão. Seu artigo mostra detalhadamente o caminho desta diferença entre o pensamento dos dois autores no que diz respeito ao ego transcendental.
}

do mundo. A questão do nosso então jovem filósofo parte da afirmativa de que a condição humana é definida por sua insuficiência de ser. Não há nada na consciência a não ser uma perpétua fuga de si mesma, um deslizar para fora de si (Sartre, 2005c), essa é a base do princípio da intencionalidade da consciência herdado de Husserl. Sendo abertura para o mundo, a consciência não pode ter interior, logo, não pode haver nela um núcleo unificador a priori - Eu formal (Je), o Eu transcendental de Kant e de Husserl em Ideen, afirma Sartrenem um pólo emanador de desejos - Eu material (Moi), o Eu desejante dos psicólogos ou "moralistas do amor próprio", como os chamava Sartre (1994). Estas duas objeções à presença do Eu na consciência, indica Luiz D. Moutinho (1995), constituem, portanto, a primeira parte do ensaio sobre a transcendência que procura negar a presença de um Eu formal (Je) e de um Eu material (Moi) na consciência. Em outras palavras, que a consciência não é um lugar, um espaço com conteúdo.O que Sartre propõe em sua descrição do psíquico - que para ele é composto pelos estados, ações e qualidades - é a inversão da compreensão clássica da tradição filosófica e psicológica. De acordo com esta compreensão, há na consciência um núcleo unificador a priori que move o sujeito no mundo, isto é, um pólo que organiza seu sentir, seu pensar e seu agir. Já em Sartre, a direção da dinâmica de ser do homem se dá pela via oposta: pela falta de ser, que é constitutiva da existência, nós unificamos nossos vividos em estados e ações. Mais ainda, somos capazes de unificar nosso estilo de ser e nos justificarmos em um caráter que remete às nossas qualidades. Assim surge para Sartre, o Ego como uma unificação sintética $a$ posteriori de tudo isto, logo, como unidade de nossa atividade psíquica. Por isso, ele afirma que "o Ego está fora, é um ser do mundo, tal como o ego de outrem" (1994, p. 43), o Ego é objeto transcendente para a consciência reflexiva ${ }^{4}$ na medida em que ele é uma unificação do psíquico, vai além da possibilidade de nossos vividos. Como é extremamente angustiante viver na incompletude do Para-si, a consciência constrói um Ego objetivado e se identifica com ele, para aplacar sua falta de ser.

Pensamos que o conto A infância de um chefe expressa tal fenomenologia do Ego, proposta no referido ensaio, já que retrata a vida de Lucien Fleurier, partindo de sua infância e acompanha o processo pelo qual, em diferentes tempos e situações, ele procura redefinir seu projeto existencial. "Estou adorável na minha roupinha de anjo" (p. 125), exclama Lucien, abrindo o conto, numa clássica cena que remete àquelas emblemáticas festas religiosas onde costumeiramente se coloca a criança fantasiada de anjo, num paralelo de sua situação com o símbolo da pureza e da inocência. A descrição de Sartre parte da in-

\footnotetext{
Sartre chama de consciência de primeiro grau ou irrefletida aquela que está voltada para o mundo, para objetos reais ou imaginários e de consciência de segundo grau ou reflexiva a que posiciona a si mesma, que põe a própria consciência como tema.
} 
fância, uma vez que, para ele, esta é considerada a fase decisiva onde se modelam preconceitos insuperáveis na tentativa da criança de desempenhar o papel social que os adultos lhe impõem (1987, p. 138). Se quisermos compreender a escolha de ser de um homem temos que realizar um movimento de "vai e vem" em sua história e recuperar este momento crucial que é a infância. E é isto que Sartre faz no conto e já nas primeiras linhas deixa claro o tema que perpassará toda a narrativa: a questão da identidade, a sua constituição na intersubjetividade e o esforço particular do homem em construir e se identificar com um Ego, um caráter, um papel social.

A história de Lucien Fleurier é, como a entende Sartre, a história de como nos constituímos como sujeitos no mundo, como nos escolhemos enquanto projeto original a partir do que fizerem de nós - e como renovamos incessantemente esse nosso projeto de ser. É também a história de uma resistência que fracassa, da formação de um caráter, do ajustamento de uma rebeldia e do conformismo que se pode assumir quando se acredita num destino. $\mathrm{O}$ título é claramente o indicativo do que o protagonista decidiu fazer de si mesmo que, "lançado ao desafio da liberdade", como explicita Luiz Carlos Maciel (1975), "decide afinal seguir a tradição familiar de respeitabilidade e se torna, em conseqüência, um fascista anti-semita típico" (57-58). Lucien, assim como os protagonistas dos outros quatro contos, está inteiramente "emparedado" por sua situação, a de "filho de chefe", não somente por seu nascimento, comenta Robert Campbell, mas por toda a sua infância e por sua educação (1949, p. 203). A questão do condicionamento social - sua situação - estará também explicitada em sua "Apresentação" à Revista Les Temps Modernes publicada em 1945:

Mas um homem não é uma árvore ou uma pedra: é preciso que ele se faça operário. Totalmente condicionado por sua classe, seu salário, a natureza de seu trabalho, condicionado até nos seus sentimentos e pensamentos, mas é ele que decide o sentido de sua condição e da de seus camaradas, é ele que, livremente, dá ao proletariado um futuro de humilhação sem trégua ou de conquista e vitória, enquanto se escolhe resignado ou revolucionário. E é por esta escolha que ele é responsável. Não há como não escolher: ele está engajado, é preciso tomar partido, a abstenção é uma escolha. (1964, p. 27-28, grifo do autor, tradução nossa).

Sartre faz questão de indicar na sua narrativa que Lucien é continuamente confrontado com sua situação sua origem, sua hereditariedade, sua classe... - e é também continuamente confrontado com um conjunto de possibilidades. Tudo isso constitui sua situação, afirma R.-M. Albérès (1958, p. 103), e é somente nela e com relação a ela que ele é livre. É, portanto, nela que Lucien faz de si mesmo aquilo que os outros fizeram dele, um chefe.
Para iniciar o problema da constituição de si em Lucien, Sartre decide colocá-lo diante da questão do gênero. Lucien tinha sido considerado por muitos adultos como uma bela mocinha: "é uma verdadeira menininha [...] como é que você se chama? Jacqueline, Lucienne, Margot?” (p. 125). Ele brinca com essas noções e coloca Lucien confuso em relação à percepção de si e a que as pessoas têm dele. Já não tinha mais certeza de não ser uma mocinha e temia que os adultos decidissem, de repente, que ele não era mais um menino. Simone de Beauvoir (2005) descreve a peculiar situação em que vive a criança, "jogada" num universo pronto, constituído sem ela, é o mundo da seriedade, o mundo dos adultos, onde cabe a ela não mais que submeter-se; "nesse universo de coisas definidas e plenas, ela acredita ser também de maneira definida e plena" (p. 36). Sua frase de abertura do segundo volume de O Segundo Sexo, publicado em 1949, trata também da constituição de si enquanto gênero e é emblemática sobre isto: "Ninguém nasce mulher: torna-se mulher" (1980, p. 9). A criança, portanto, acredita no ser de seus pais e professores, pois está a eles submetida; são eles que lhe fornecem uma identidade na qual ela deve, também, acreditar. É neste sentido que Sartre brinca com a condição de gênero de Lucien que, diante de um universo que lhe é imposto, não sabe mais se conseguirá sustentar sua condição de ser: "talvez isso já esteja acontecendo, e eu seja uma menina", pensa Lucien (p. 126).

A infância, neste contexto, representa a fase do mundo pronto, do constituído, da irresponsabilidade do Para-si, que sendo "insuficiência de ser", se apóia na definição de mundo dada pelos adultos para poder se colocar perante o vazio da existência. $\mathrm{O}$ mundo aparece à criança com um sentido definido: a mamãe é para se amar, o jardim é para brincar, a escola é para estudar, o banheiro é lugar das coisas sujas - não é à toa que Sartre, por diversas vezes ao longo do conto, faz alusão à privada como o "refúgio" de Lucien; é também no banheiro que ele relata em As Palavras (1964) que experimentou a sensação de que Deus existia ${ }^{5}$ (p. 65). A partir desta formulação de "mundo com sentido definido", parte um interessante momento da narrativa em que Lucien, logo após ser interrogado por um padre sobre se prefere "mamãe ou Nosso Senhor?", fica novamente confuso e sai em disparada rompendo os limites do muro do jardim, indo além, aonde lhe era proibido ultrapassar. Parece que Sartre nos indica um momento crucial do processo de constituição de si na criança, exatamente o momento em que lhe foi possível vislumbrar que suas respostas "com um senti-

\footnotetext{
"Durante muitos anos ainda, entretive relações públicas com o Todo-poderoso; na intimidade deixei de freqüentá-lo. Uma só vez experimentei a sensação de que Ele existia. Eu brincara com fósforos e queimara um pequeno tapete; estava dissimulando meu crime, quando de súbito Deus me viu, senti Seu olhar dentro de minha cabeça e sobre minhas mãos; eu rodopiava pelo banheiro, horrivelmente visível, um alvo vivo. A indignação me salvou: enfureci-me contra tão grosseira indiscrição, blasfemei, murmurei como meu avô: 'Maldito nome de Deus, nome de Deus, nome de Deus'. Nunca mais ele me contemplou." (1964, p. 65).
} 
do definido" vacilam, quando não pode mais recorrer aos modelos absolutos dados pelos adultos e ele tem que decidir. "Mamãe ou Nosso Senhor?", ressoa na cabeça de Lucien a frase do padre. Esta pergunta sem resposta imediata faz com que o menino vá se refugiar do "outro lado do muro":

Lucien não devia jamais sair do jardim, era proibido... mas nesse dia sentia desejos de desobedecer...o muro estava enegrecido, as urtigas eram plantas más e nocivas...e um cheiro do proibido, poderoso, pútrido e tranqüilo lhe enchia as narinas (p. 132).

O vacilo da resposta estremeceu a serenidade do mundo infantil de Lucien, e Sartre apresenta ao leitor o momento questionador da criança, um momento de constituição de autonomia. Desde então, o menino passa a abrir os brinquedos para ver o que tem dentro e de que são feitos. Diverte-se em irritar a empregada Germaine e surpreende-se em não conseguir fazer o mesmo com uma árvore: "Árvore burra, castanheiro sujo [...] a árvore permaneceu tranqüila, tranqüila como se fosse de pau” (p. 133). Neste momento crítico, aquela criança começa a diferenciar o modo de ser das coisas e o da realidade humana.

Depois desta reviravolta Lucien cai numa profunda sonolência. Sua cabeça parece estar cheia de cerração, como que uma espécie de névoa a embaçar sua visão do mundo e de si mesmo. Sartre relata um episódio em que Lucien vai à fábrica do pai, e então, surge pela primeira vez, a pergunta decisiva do conto: "Será que me tornarei também um chefe?” (p. 138). Porém, esta função social não pode ser ainda assumida pelo menino. Ainda não é chegada a hora de herdar o papel que resolveria a demasiada questão que é existir. A sonolência permanece e Lucien precisa continuar a suportar, sem justificativas, sua inconsistência de ser. Não sabemos o que Lucien se tornará, o que sabemos é da sua educação, da sua origem, das pequenas possibilidades de autonomia. Estes são os fatos, estes são os dados que são apresentados ao leitor sobre a vida de Lucien. Utilizando-se de uma forma de narrativa similar ao "fluxo de consciência", Sartre nos faz invadir as inquietações mais íntimas desta consciência, a ponto de sentir o esforço que Lucien faz para se colocar diante de si e olhar-se. É neste esforço que o menino posiciona o seu entorpecimento e logo a sonolência se desfaz. Ele transcende sua falta de ser e se objetiva em um questionamento acabado: “Quem sou eu?” (p. 148). Na tentativa de responder ao posicionamento reflexivo, Lucien vai buscar argumentos fechados e acabados: "sou um bom aluno... tenho boas notas” (p. 148), mas logo os contrapõe a "não gosto de estudar... Não dou importância a nada. Nunca serei um chefe" (p. 148). Frente à fragilidade destes atributos, vê-se obrigado a concluir: "Eu não existo,... a existência é uma ilusão” (p. 149). Na seqüência deste episódio, Lucien encontra Babouin, seu professor de filosofia, e o interroga se é possível sustentar a tese de que ele não existe. A resposta de Babouin é cartesianamente contundente: "Goghito ergo çoum [sic). O senhor existe pois duvida da sua existência”(p. 149).

Tendo chegado ao crucial questionamento sobre o sentido da existência, Lucien como que servindo de metáfora para o que Sartre denomina de espírito de seriedade, que representa a má-fé das classes dominantes, resolve esquivar-se da angústia provocada pela sua insuficiência e justificar-se nos "grandes ídolos explicativos de sua época” (Sartre, 2001). A partir do encontro com o professor, Sartre emprestará a seu protagonista as mais diversas espécies de rótulos e de justificativas. Primeiro, o cogito cartesiano referido por Babouin, depois os complexos psicanalíticos aprendidos com seu amigo Berliac. Posteriormente, receberá o rótulo de "desajustado" dado por Bergère. Este último se tornará o relacionamento mais complicado de Lucien, onde preso no jogo de espelho do olhar do outro, acabará agindo de forma bastante contrária aos seus desejos, a fim de não frustrar a expectativa que Bergère faz dele. Terá, assim, sua primeira experiência sexual com ele, e desta desastrada tentativa herdará o rótulo de pederasta. Após este conflitante episódio, o conto terá uma nova reviravolta e Lucien passará a se apoiar na sua "saúde moral" e nos valores sólidos de sua família. “TENHO DIREITOS. Direitos!” (p. 216), exclama aliviado, utilizando esse novo jargão como sua fuga salvadora e necessária. Para Luiz Carlos Maciel, Sartre discute que não temos um "caráter", mas optamos por um "projeto original" e o renovamos continuamente. "Podemos, no processo", continua ele,

assumir sempre nossa liberdade fundamental ou fabricarmos um "caráter" para fugir dela. Acreditamos nele, comportamo-nos de acordo com ele, etc., mas ele não passa de um mito: um expediente de má-fé para a omissão e a irresponsabilidade. Sartre narra, portanto, como se forma o caráter de Lucien Fleurier (1975, p. 58).

Lucien faz novas amizades e tenta a todo custo se libertar do peso de seu passado. Conhece Lemordant que a seus olhos tem a aparência de uma rocha e demonstra estar sempre em plena consciência de si mesmo. Este novo amigo é envolvido com questões politizadas, porém anti-semitas, mas é justamente a solidez de uma moral que o jovem Lucien procura para aplacar sua incompletude: "Lucien Fleurier tem horror dos judeus"; "Lucien Fleurier é um desarraigado". Assim o jovem passa a pertencer ao círculo de amigos de Lemordant e a desempenhar um papel dentro deste gruposendo chamado pelos novos amigos por seu sobrenome: "eis que, de novo, lhe ofereciam um caráter e um destino, um meio de escapar às tagarelices inesgotáveis de sua consciência, um método para definir-se e apreciar-se (p. 198).

O conto termina com um emblemático episódio no qual Lucien, numa festa, vira as costas para um judeu e 
vai embora. Num primeiro momento, ele fica atormentado pelo possível fato de ser mal interpretado por seus amigos anfitriões do evento. Mas logo é justificado por um deles, Guigard, que se desculpa pela gafe cometida de querer apresentar "Lucien Fleurier que tem horror aos judeus" a um deles: "Meus pais acham que você tem razão, que você não podia agir de outro modo, desde que tem uma convicção. Lucien saboreou a palavra ‘convicção’” (p. 212213). Estava novamente justificado pelo olhar do outro e isto era suficiente para consumar sua metamorfose. Em meio às suas reflexões sentia orgulho de si mesmo, estava justificado por suas convicções que faziam valer os seus DIREITOS: "naquele café, uma hora antes, havia entrado um adolescente gracioso e indeciso; agora, quem de lá saía era um homem, um chefe entre os franceses” (p. 218). Sartre, ironicamente, fecha o conto com a seguinte exclamação: "vou deixar crescer o bigode” (p. 218).

Acompanhando o processo existencial de Lucien, ficam claras as idéias de Sartre sobre a forma como o Para-si, livre consciência no mundo, constitui e se identifica com um Ego projetado diante de si. Ele desenha a trajetória do personagem de forma a colocar o leitor em contato com as diversas situações que compõe a saga de uma consciência no mundo e a constituição de si. Num primeiro momento, "Lucien-criança” lida com sua liberdade de forma irresponsável e irrefletida, simplesmente acredita no que lhe é dado. Quando surgem os primeiros traços de vacilação do mundo pronto dos adultos, "Lucienadormece-para-si”, quer dizer, uma sonolência profunda o invade de forma a não posicionar a angústia provocada por sua incompletude. O "Lucien-adolescente" vai buscar no mundo, fora de si, explicações para o vazio que sente, justificativas acabadas que o objetivem de maneira que não tenha que lidar com a angústia, mas essas tentativas ainda estremecem pois não estão de acordo com o projeto fundamental do rapaz. Enfim, quando consciência e mundo se afinam na resolução de seu caráter a metamorfose está consumada. A existência de Lucien encontra sua justificativa na constituição de um caráter que ele pode tomar posse e se identificar.

A trajetória existencial de Fleurier pode, assim, ser entendida como um primeiro esboço do método biográfico posteriormente desenvolvido por Sartre em célebres trabalhos, isto porque desde o início da narrativa percebemos a inquietante indagação do menino pelo sentido de sua existência. Todas as passagens do conto apontam para a tentativa de Lucien de constituir sua identidade, objetivada em um Ego que lhe defina e lhe atribua sentido. Sua saga é encontrar uma resposta pra a eterna pergunta: “Quem sou eu?” Para Sartre, este núcleo sólido e opaco que é o Ego existe, mas não como um "habitante" de uma vida interior, ele é constituído fora como um objeto transcendente que a consciência intencional põe em cena para aplacar sua incompletude de ser. “...afinal de contas tudo está fora, tudo, até nós mesmos: fora, no mundo, entre os outros. Não é em sabe-se lá qual retrai- mento ${ }^{6}$ que nos descobriremos: é na estrada, na cidade, no meio da multidão, coisa entre as coisas, homem entre os homens" (Sartre, 2005c).

\section{Referências}

Albérès, R. M. (1958). Jean-Paul Sartre. Belo Horizonte: Itatiaia.

Beauvoir, S. (2005). Por uma moral da ambigüidade. Rio de Janeiro: Nova Fronteira

Beauvoir, S. (1980). O Segundo Sexo (Vol. 2). Rio de Janeiro: Nova Fronteira.

Campbell, R. (1949). Jean-Paul Sartre, o una literatura filosofica. Buenos Aires: Argos.

Contat, M. \& Rybalka, M. (1970). Les Écrits de Sartre: chronologie, bibliographie, commentée. Paris: Gallimard.

Lottman, H. R. (1987). A Rive Gauche. Escritores, artistas e políticos em Paris 1930-1950 (2. ed.). Rio de Janeiro: Guanabara.

Maciel, L. C. (1975). Sartre, vida e obra. Rio de Janeiro: Paz e Terra.

Mészáros, I. (1991). A obra de Sartre: busca da liberdade. São Paulo: Ensaio.

Mouillie, J-M. (2000). Sartre: conscience, ego ET psychè. Paris: PUF.

Moutinho, L. D. (1995). Sartre: Psicologia e Fenomenologia. São Paulo: Brasiliense.

Sartre, J-P. (1996). La transcendance de l'Ego. Esquisse d'une description phénoménologique. Introduction, notes et appendices par Sylvie Le bon. Paris: J. Vrin.

Sartre, J-P. (1994). A Transcendência do Ego: esboço de uma descrição fenomenológica. Lisboa: Colibri.

Sartre, J-P. (1987). Questão de Método. Sartre (Coleção Os Pensadores). São Paulo: Nova Cultural.

Sartre, J-P. (2001). O Ser e o Nada: ensaio de ontologia fenomenológica. Petrópolis: Vozes.

Sartre, J-P. (2005a). A náusea. Rio de Janeiro: Nova Fronteira.

Sartre, J-P. (2005b). O muro. Rio de Janeiro: Nova Fronteira.

Sartre, J-P. (2005c). Uma idéia fundamental da fenomenologia de Husserl: a intencionalidade. Em Jean-Paul Sartre, Situações I: criticas literárias. São Paulo: Cosac Naify.

Sartre, J-P. (1964). Présentation des Temps Modernes. Em JeanPaul Sartre, Situations, II. Paris: Gallimard.

Sartre, J-P. (1964). As Palavras. São Paulo: Difusão Européia do Livro.

6 Preferimos: "Não é em nenhum refúgio que nos descobriremos: é na rua, na cidade, no meio da multidão, coisa entre as coisas, homem entre os homens". 
Sartre, J-P. (1999). Que é a Literatura? São Paulo: Ática.

Sass, S. D. (1999). A concepção sartriana de ego transcendental. Educação e Filosofia, 13, 26, 263-274.

Silva, F. L. (2004). Ética e literatura em Sartre: ensaios introdutórios. São Paulo: Editora UNESP.

Winock, M. (2000). O século dos intelectuais. Rio de Janeiro: Bertrand Brasil.

Carolina Mendes Campos - Mestre em Psicologia pela Pontifícia Universidade Católica do Rio de Janeiro (PUC-RJ) e Professora da Especialização em Psicologia Clínica do Instituto de Psicologia Fenomenológico-Existencial do Rio de Janeiro (IFEN). Endereço Institucional: Rua Barão de Pirassununga, 62 - Tijuca, Rio de Janeiro / RJ. Email: carolinamendescampos@gmail.com

Fernanda Alt - Mestre em Psicologia Social pela Universidade do Estado do Rio de Janeiro (UERJ) e Professora Substituta da Universidade Federal do Rio de Janeiro (UFRJ). Endereço Institucional: Av. Pasteur, 250 - Pavilhão Nilton Campos. CEP: 22290-240, Rio de Janeiro / RJ. Email: fernanda.alt.fg@gmail.com

Ariane Patrícia Ewald - Professor Adjunto do Instituto de Psicologia e do Programa de Pós-Graduação em Psicologia Social da Universidade Federal do Rio de Janeiro (UERJ). Endereço Institucional: Universidade do Estado do Rio de Janeiro. Rua São Francisco Xavier, 524 (10 andar). Maracanã. CEP: 20550.900 (Rio de Janeiro / RJ). Email: arianeuerj@yahoo.com.br

Recebido em 28.07.09

Aceito em 25.10.09 